\title{
Ensino remoto emergencial no estado de Mato Grosso: desafios presentes no ensino
}

\section{da Educação Física}

\author{
Emergency remote education in the state of Mato Grosso: challenges present in physical education \\ teaching
}

Educación remota de emergencia en el estado de Mato Grosso: retos presentes en la enseñanza de

la educación física

Recebido: 11/11/2021 | Revisado: 19/11/2021 | Aceito: 25/11/2021 | Publicado: 03/12/2021

\author{
Diana de Souza Moura \\ ORCID: https://orcid.org/0000-0002-7240-7307 \\ Secretaria de Estado de Educação de Mato Grosso, Brasil \\ E-mail: diannamoura95@hotmail.com \\ Robson Alex Ferreira \\ ORCID: https://orcid.org/0000-0003-2138-2928 \\ Universidade do Estado de Mato Grosso, Brasil \\ E-mail: robsonalex@unemat.br \\ Viviany da Silva Brugnhago \\ ORCID: https://orcid.org/0000-0001-6557-6850 \\ Universidade Estadual de Londrina, Brasil \\ E-mail: vivianybrugnhago@gmail.com \\ Marcela Ariete dos Santos \\ ORCID: https://orcid.org/0000-0003-2271-6555 \\ Universidade do Estado de Mato Grosso, Brasil \\ E-mail: marcela.ariete@unemat.br
}

\begin{abstract}
Resumo
A implantação do Ensino Remoto Emergencial (ERE) se fez necessária durante a pandemia da Covid-19, com isso, a escola, os alunos e professores tiveram que se reinventar no que diz respeito às relações de ensino e aprendizagem. Nesta direção, o objetivo desse trabalho foi analisar a percepção dos professores sobre essas transformações ocorridas, bem como identificar os principais desafios que enfrentaram com o ensino da Educação Física neste novo modelo. Optou-se por uma pesquisa do tipo qualitativa descritiva. A amostra foi composta por 11 professores da rede municipal e estadual de Mato Grosso que fazem parte do Programa de Mestrado Profissional em Educação Física. Para a coleta de dados foram realizadas entrevistas e a análise dos dados ficou organizada por eixos temáticos. Os principais resultados apontaram que os professores tiveram dificuldades relacionadas principalmente à utilização das tecnologias digitais e na comunicação com os estudantes. Os professores destacaram também que ocorreram mudanças na forma de oferta dessa disciplina, as aulas que antes eram na maioria das vezes prática, passaram a ser mais conceituais. Ainda assim, os professores deixaram evidente que essas transformações proporcionaram avanço de maneira mais rápida no que tange o uso de tecnologias digitais nas aulas, além da aproximação da família com o ambiente escolar. Deste modo, acreditamos que o ERE gerou grandes desafios e dificuldades para a escola, professores e família, assim como também proporcionou grandes aprendizados que serão levados para o ensino presencial, quando este retornar.
\end{abstract}

Palavras-chave: Educação física; Tecnologias digitais; Escola; Professores.

\begin{abstract}
The Emergencial Remote Teaching (ERT) was necessary during the COVI-19 pandemic. Thus, school, students and teachers had to get readaption about teaching and learning process. This paper aimed to analyze the teacher's perceptions about those transformations, also to identify the main challenges faced in Physical Education Teaching. The paper's approach was descriptive qualitative. Eleven teachers from municipal educacional staff that are Physical Education Master's Degree students were our sample. Interviews were used for data harvest and data analyses were organized by tematic axises. The main findings showed the subjects had trouble using digital technologies, and had trouble reaching the students. There were a lot of changes on the way that Education Physical classes happen, one of them, a frequent way of conceptual teaching. The changes also provided faster advances in the use of digital technologies in classes and bringing the family closer to the school environment. We believe that the ERT generated great challenges and difficulties for the school, teachers and family, as well as providing great learning that will be taken to presencial teaching when it returns.
\end{abstract}

Keywords: Physical education; Emergency Remote Teaching; Teachers. 


\section{Resumen}

La implementación de la Enseñanza Remota de Emergencia (ERE) fue necesaria durante la pandemia Covid-19, con esto, la escuela, estudiantes y docentes tuvieron que reinventarse en lo que respecta a las relaciones de enseñanza y aprendizaje. En esta dirección, el objetivo de este trabajo fue analizar la percepción de los docentes sobre estos cambios, así como identificar los principales desafíos que enfrentaron con la enseñanza de la Educación Física en este nuevo modelo. Optamos por una investigación cualitativa descriptiva. La muestra estuvo conformada por 11 docentes de la red municipal y estatal de Mato Grosso que forman parte del Programa de Maestría Profesional en Educación Física. Para la recolección de datos se realizaron entrevistas y el análisis de datos se organizó por ejes temáticos. Los principales resultados mostraron que los docentes tenían dificultades principalmente relacionadas con el uso de tecnologías digitales y la comunicación con los estudiantes. Los docentes también destacaron que hubo cambios en la forma en que se ofrecía esta disciplina, las clases que eran en su mayoría prácticas, se volvieron más conceptuales. Aun así, los docentes dejaron claro que estas transformaciones proporcionaron un avance más rápido en cuanto al uso de las tecnologías digitales en las clases, además de acercar a la familia al entorno escolar. De esta forma, creemos que el ERE generó grandes retos y dificultades para el colegio, el profesorado y la familia, además de brindar un gran aprendizaje que se llevará a la enseñanza presencial cuando regrese.

Palabra clave: Educación física; Tecnologías digitales; Colegio; Maestros.

\section{Introdução}

No ano de 2020, mais precisamente no dia 11 de março, toda a população mundial foi surpreendida com a divulgação da pandemia da Covid-19. Nesse momento não se tinha conhecimento sobre o vírus, se conhecia apenas a forma de transmissão. Como uma das medidas para conter a transmissão da Covid-19 foi o distanciamento social, as escolas foram uma das primeiras instituições a serem fechadas. Nas escolas estaduais do Estado de Mato Grosso, isto se deu no dia 17 de março de 2020 , através de um informativo sobre o início da pandemia no Estado.

O Governo brasileiro publicou a Portaria $n^{\circ} 343$, de 17 de março de 2020, que dispôs sobre a substituição das aulas presenciais por aulas em meios digitais enquanto durasse a pandemia de Covid-19 (Brasil, 2020). A partir dessa portaria as escolas e universidades tiveram que se organizar para o ensino remoto e assim começavam os desafios. Nas escolas estaduais do estado de Mato Grosso as aulas ficaram totalmente paralisadas até o mês de julho de 2020, enquanto em alguns municípios as aulas remotas se iniciaram quase que imediatamente.

Dentre as diversas disciplinas que compõem a grade curricular dos discentes na educação básica, está a Educação Física. Esta é um componente curricular obrigatório e se encontra presente em todas as escolas, onde as aulas aconteciam de maneira presencial para todas as turmas. Essa realidade mudou a partir de 2020, trazendo à tona o início do Ensino Remoto Emergencial (ERE). As aulas de Educação Física de maneira remota passaram a ser uma grande preocupação dos professores, afinal, uma de suas especificidades está na vivência da diversidade das práticas corporais relacionadas as unidades temáticas propostas pela Base Nacional Curricular Comum - BNCC (Brasil, 2017).

Dessa forma, vários questionamentos foram surgindo para subsidiar nosso trabalho: como ensinar a Educação Física de modo remoto? Os estudantes participariam dessas aulas de maneira com que pudéssemos contribuir de modo significativo, assim como ocorreria no ensino presencial? Que saberes proporcionaríamos aos discentes de maneira com que eles pudessem realizar individualmente as atividades, sem a presença física do professor?

A partir destes questionamentos, o objetivo desse estudo foi analisar a percepção dos professores sobre os desafios enfrentados no ensino da Educação Física durante o período de aulas remotas.

\section{Referencial Teórico}

No início do ano letivo, mais precisamente no mês de março do ano de 2020, todos os profissionais da educação e estudantes do Estado de Mato Grosso se preparavam para o retorno das atividades escolares. Mas antes que isso acontecesse houve a suspensão do retorno das aulas, devido a pandemia de Covid-19, como medida de prevenção da transmissão do vírus. A partir desse momento, estados e municípios passaram a decretar a suspensão das aulas. 
Buscando o retorno das atividades escolares, foi publicada pelo Governo Federal a Portaria no 343 (Brasil, 2020), que dispôs sobre a substituição das aulas presenciais por aulas em meios digitais enquanto durar a pandemia de Covid-19. As escolas precisariam se organizar para adotar o ERE.

Nesse contexto, é importante destacar a diferença entre ERE e Educação à Distância (EAD), que muitas vezes acabam sendo confundidos. Segundo Rodrigues (2020), na EAD existem concepções teóricas, fundamentos metodológicos e especificidades que sustentam essa modalidade. Já o ERE, de acordo com Hodges et al. (2020), é uma adaptação curricular temporária que permite utilizar uma forma alternativa de ensino devido a situação de crise, para que as atividades de ensino possam continuar enquanto durar o distanciamento social.

Inicialmente a Secretaria de Estado de Educação optou pela suspensão total das atividades nas escolas, não acontecendo nenhum atendimento presencial ou remoto, permanecendo assim por alguns meses. A partir do dia 15 de julho todos os profissionais começaram a se preparar para o início do ano letivo através do ERE. Foram realizadas formações em como lecionar no modelo a ser adotado, bem como sobre a plataforma digital que seria utilizada e como os estudantes sem acesso à internet acompanhariam as aulas. Sendo assim, todas as escolas estaduais do Estado de Mato Grosso iniciaram o seu ano letivo no dia 03 de agosto de 2020, utilizando a plataforma Microsoft Teams para a realização das aulas.

Dessa forma, professores e estudantes precisaram se adaptar ao novo método para a realização das aulas mediado agora pelo uso de tecnologias digitais. Isto demandou que professores e estudantes migrassem "para a realidade online, transferindo e transpondo metodologias e práticas pedagógicas típicas dos territórios físicos de aprendizagem” (Moreira \& Schlemmer, 2020, p. 7).

Todos os componentes curriculares precisaram passar por mudanças e adaptações e com a Educação Física não foi diferente. No entanto, a Educação Física possui uma particularidade, está voltada majoritariamente para a prática corporal relacionada a cultura corporal de movimento. De acordo com Betti \& Zuliani (2002, p. 75) "é tarefa da Educação Física preparar o aluno para ser um praticante lúcido e ativo, que incorpore o esporte e os demais componentes da cultura corporal em sua vida, para deles tirar o melhor proveito possível".

As aulas de Educação Física se tornaram um grande desafio para os professores, pois, anteriormente a esse momento pandêmico, estas aulas sempre foram realizadas de forma presencial. Havia o contato diretamente dos professores com os estudantes, as aulas em sua maioria ocorriam em ambientes abertos ou, quando não havia está possibilidade, ao menos com a presença efetiva do professor. Com a mudança, os professores precisaram buscar alternativas para a continuidade das aulas de maneira que fosse possível proporcionar as mesmas oportunidades aos estudantes.

Acreditamos assim como Betti \& Zuliani (2002) que seja papel da Educação Física fazer com que os discentes reconheçam, experimentem e se integram aos componentes da cultura corporal de movimento. Por isso, acredita-se que:

A Educação Física deve assumir a responsabilidade de formar um cidadão capaz de posicionar-se criticamente diante das novas formas da cultura corporal de movimento... A Educação Física enquanto componente curricular da Educação Básica deve assumir então uma outra tarefa: introduzir e integrar o aluno na cultura corporal de movimento, formando o cidadão que vai produzi-la, reproduzi-la e transformá-la (Betti \& Zuliani, 2002, p. 75).

Como um componente curricular presente no contexto escolar, a Educação Física também se encontra na BNCC documento que rege a educação nacional, onde se enquadra como componente da área de linguagens. A BNCC aponta as unidades temáticas a serem trabalhadas, sendo elas: brincadeiras e jogos, Esportes, Ginásticas, Danças, Lutas e Práticas Corporais de aventura (Brasil, 2017).

Dentro das unidades temáticas contidas na BNCC são apresentados os objetivos e habilidades a serem desenvolvidas junto aos estudantes no decorrer de cada ano letivo. Muitas destas habilidades são alcançadas por meio das vivências ao se movimentar. Dessa forma, as aulas de Educação Física se tornaram mais desafiadoras ainda, uma vez que a presença do professor 
e estudantes no chão da escola não ocorreria e as habilidades, por sua vez, não seriam alteradas devido a situação emergencial vivida.

Ainda, é importante destacar que os desafios presentes nas aulas de Educação Física já se faziam bastante presentes no ensino presencial, desafios esses relacionados a infraestrutura, falta de materiais disponíveis, valorização da disciplina de Educação Física, entre outros (Rufino, et al., 2017).

Assim, se fez necessário adaptações que não fugissem das unidades temáticas presentes na Educação Física. De acordo com a BNCC o professor tem a liberdade de optar por trabalhar com qualquer prática corporal presente nas diferentes etapas de ensino, desde que haja uma progressão no conhecimento perpassado para os estudantes, facilitando a organização do conhecimento. $\mathrm{O}$ documento ainda indica a possibilidade de adaptação das atividades propostas de acordo com cada contexto escolar (Brasil, 2017).

Neste contexto, os professores precisaram se adaptar a novos modelos de ensino e aprendizagem, para que fosse possível a continuação do ano letivo de maneira online, utilizando computadores e dispositivos móveis. Dialogando com esse cenário remoto, de acordo com Garcia et al. (2012, p. 82), a

[...] tecnologia digital interativa é uma produção criada pelo homem que pressupõe a comunicação interativa, ou seja, capaz de intervenção pelos sujeitos no conteúdo ou programa com o qual interage e que tem, na ferramenta tecnológica, a mediadora desse processo, que é dialógico, levando em consideração os feedbacks ao usuário.

Em relação ao ambiente escolar, de acordo com Castaman \& Rodrigues (2020, p. 9) os docentes precisaram por "força de urgência, em um curto espaço de tempo, reaprender/refazer sua forma de acesso aos estudantes, encaminhar atividades e acompanhar de modo mais individual a trajetória de cada um".

Desde que se iniciou o ERE muito se tem falado da utilização de tecnologias digitais, pois houve a necessidade da utilização desta para que houvesse a continuação do ano letivo. Estas tecnologias são ferramentas que auxiliam os professores durante as aulas devido ao atual momento, mas no ERE existem situações que estão além da utilização de tecnologias. Segundo Moreira \& Schlemmer (2020, p. 9) “o processo é centrado no conteúdo e a comunicação é predominantemente bidirecional, do tipo um para muitos, no qual o professor protagoniza videoaula ou realiza uma aula expositiva por meio de sistemas de web conferência.".

As escolas públicas sempre enfrentaram diversos problemas e dificuldades. Com a migração do ensino presencial para o ERE essas dificuldades se evidenciaram ainda mais, como por exemplo, os casos da evasão escolar e a desigualdade econômica. Neste sentido, Castaman \& Rodrigues, (2020, p. 3) destacaram que o ERE acabou "oportunizando inclusive a evasão e o aumento da desigualdade, assim como o desconforto de ter que assumir o processo de ensino e aprendizagem como condição de autonomia, de empoderamento e de autodeterminação".

A desigualdade de oportunidades para o acompanhamento das aulas de maneira remota está relacionada aos aspectos econômicos, pois muitos estudantes e professores não possuem todas as condições tecnológicas necessárias para a continuidade das aulas de maneira online. Mesmo diante deste cenário, as atividades escolares precisavam continuar para que o prejuízo acadêmico não fosse maior.

\section{Metodologia}

Essa pesquisa, foi aprovada pelo Comitê de Ética da Universidade do Estado de Mato Grosso sob o parecer de número 5.100.253. Optou-se pela realização de uma pesquisa de campo descritiva qualitativa. A pesquisa qualitativa, segundo Minayo et al. (2007, p. 21) trabalha "como o nível de realidade que não pode ser quantificado. Ou seja, ela trabalha com o universo de significados, motivos, aspirações, crenças, valores e atitudes [...] dos processos e dos fenômenos que não podem ser reduzidos à operacionalidade de variáveis". Cujos objetivos são caracterizados como sendo do tipo exploratório e descritivo. 
Sob a perspectiva de Prodanov \& Freitas (2013), a pesquisa descritiva possui as seguintes características:

O pesquisador apenas registra e descreve os fatos observados sem interferir neles. Visa a descrever as características de determinada população ou fenômeno ou o estabelecimento de relações entre variáveis. Envolve o uso de técnicas padronizadas de coleta de dados: questionário e observação sistemática. Assume, em geral, a forma de Levantamento. Tal pesquisa observa, registra, analisa e ordena dados, sem manipulá-los, isto é, sem interferência do pesquisador. Procura descobrir a frequência com que um fato ocorre, sua natureza, suas características, causas, relações com outros fatos. Assim, para coletar tais dados, utiliza-se de técnicas específicas, dentre as quais se destacam a entrevista, o formulário, o questionário, o teste e a observação. (p. 51-52)

\section{Participantes}

Participaram da pesquisa11 professores de Educação Física que atuam na rede municipal e estadual do estado de Mato Grosso e que são atualmente mestrandos do Programa de Mestrado Profissional em Educação Física. Este número de participantes correspondeu a 100\% dos professores do Mestrado Profissional em Educação Física que atuam no estado de Mato Grosso. A idade dos participantes ficou compreendida entre 28 e 51 anos e o tempo de magistério variou entre 5 anos e 30 anos de atuação no ambiente escolar. Todos os participantes possuem pós-graduação. Neste estudo eles foram representados por números a fim de preservarmos sua identificação.

\section{Coleta de Dados}

Para a coleta de dados utilizamos a entrevista como instrumento de pesquisa. Sendo uma entrevista semiestruturada composta por cinco questões que foram elaboradas pelos pesquisadores, a partir das experiências vivenciadas no ERE, o tempo em média das entrevistas foram entre 7 e 15 minutos. Optou-se pela entrevista devido a sua flexibilidade e por ser um dos instrumentos mais utilizados em pesquisas qualitativas. Segundo Gil (2008, p. 109),

Enquanto técnica de coleta de dados, a entrevista é bastante adequada para a obtenção de informações acerca do que as pessoas sabem, creem, esperam, sentem ou desejam, pretendem fazer, fazem ou fizeram, bem como acerca das suas explicações ou razões a respeito das coisas precedentes.

As entrevistas foram realizadas de forma individualizada, em horário e dia estabelecido pelos próprios sujeitos da pesquisa, sendo realizadas em ambiente virtual via Google Meet. Todos os sujeitos assinaram o Termo de Consentimento Livre e Esclarecido antes da participação na coleta dos dados.

\section{Análise dos dados}

Para a análise dos dados optou-se pelos eixos temáticos a partir dos procedimentos adotados por Rinaldi (2009): leitura preliminar dos dados; definição de unidades de conteúdo a partir dos dados; categorização dos dados; e, fase de interpretação dos resultados.

\section{Resultados e Discussão}

Foram traçados cinco eixos temáticos, denominados: o Ensino Remoto não atende a todos; autoavaliação sobre os conhecimentos das tecnologias digitais; dificuldades encontradas com processo ensino aprendizagem; estratégias adotadas no ERE; e, por fim, contribuições do Ensino Remoto para o ensino presencial, apresentados a seguir.

O primeiro eixo temático foi denominado de: o Ensino Remoto não atende a todos e surgiu a partir do questionamento que investigou a percepção dos professores sobre os desafios enfrentados no ensino da Educação Física durante o ERE. Destacamos as seguintes falas extraídas: 
[...] não há como a gente avaliar como algo $100 \%$ positivo, que a gente sabe que não estamos alcançando os alunos em sua totalidade, a gente alcança uma minoria de alunos que são os que tem acesso à internet, esses que estão diariamente interagindo conosco, mas a grande maioria dos alunos estão remotos pelo material impresso, pelas apostilas... e aí não acontece a interação em si com o professor, então assim eu avalio como infelizmente não de maneira positiva em 100\%, mas ao mesmo tempo é a única forma possível nesse momento [...] (Professor 1).

Em questões técnicas, eu avalio bem deficiente, se a gente for levar em conta a educação pública, o público-alvo de baixa renda, enfim ele não se tornou acessível a todos aqueles que deveriam ter acesso as aulas remotas, em questões técnicas, os alunos não tiveram acesso. Eu tive muito problema com acesso dos alunos, acesso à internet, acesso as tecnologias, em termos técnicos achei deficiente [...] entendo que os alunos precisavam ter acesso as aulas, entendo, acho muito válido ter esse contato com os alunos [...] (Professor 7).

O ensino remoto na verdade ele é diferente do ensino a distância, porque o que a gente percebe é que foi um movimento brusco, não planejado e que foi improvisado para tentar minimizar os efeitos da pandemia, então esse processo criou dificuldades porque a gente numa educação a distância, você tem todo um amparo, um aparato de pessoas e de materiais já organizado previamente, com uma quantidade de tecnologia já organizada previamente para você poder atuar como professor, então você vai ter o tutor, vai ter o professor da disciplina, você já tem o material preparado e no nosso caso o ensino remoto, ele foi uma coisa brusca e a gente acaba sendo pego de surpresa e tendo que transmitir a nossa aula prática, a nossa aula presencial, tentar organizar para que ela se torne uma aula virtual em que o aluno não vai tá próximo a você (Professor 9).

Com as respostas podemos perceber que os professores relatam não conseguir alcançar os estudantes de forma significativa e apenas os estudantes que possuem acesso à internet tiveram a possibilidade de acompanhar as aulas em tempo real juntamente com os professores. Apesar disso, os professores percebem que o ERE emergiu da necessidade de dar continuidade as aulas após o início da pandemia da Covid- 19. Desta forma, com o início do ERE se evidenciou as dificuldades relacionadas principalmente ao acesso dos estudantes nas aulas, coisa que não acontecia durante o ensino presencial.

Deste modo, professores e alunos habituados com as aulas presenciais, tiveram que se adaptar ao ERE, mediado pelas tecnologias. Essa transição do ensino presencial para o ERE não é algo simples, pois exigiu de professores e alunos novas aprendizagens principalmente relacionadas à integração das tecnologias digitais da informação e comunicação (TDICs) ao ensino, a repensar a estrutura das aulas e as abordagens pedagógicas, mas também evidenciou os desafios de acesso às tecnologias, principalmente pela população mais pobre e vulnerável (Godoi, et al., 2021, p. 4).

A implementação do ERE exigiu muito por parte dos professores, além da adaptação urgente às tecnologias digitais, evidenciando, de maneira significativa, as dificuldades de acesso às tecnologias e à internet, vivenciada principalmente pela população mais pobre, tornando desigual a forma de ensino e ressaltando a preocupação dos professores com os estudantes que não possuem as mesmas possibilidades.

Ficando evidente as dificuldades em relação ao processo de ensino aprendizagem durante o ensino remoto, como: os estudantes que acompanham as aulas somente pelos materiais apostilados tendem a não ter suas dúvidas e dificuldades sanadas. Neste sentido, Honorato e Marcelino (2020) afirmam que pode haver complicações relacionadas ao processo de ensinoaprendizagem.

O próximo eixo elencado foi: autoavaliação sobre os conhecimentos das tecnologias digitais e surgiu a partir da indagação que avaliava a percepção do professor em manusear as ferramentas digitais necessárias para lecionar no ensino remoto.

Eu me qualifico no básico, porque eu faço o básico para eu poder dar aula, então eu ainda não fui além, muitas coisas a gente sabe, que tem muitas coisas da tecnologia que vai além [...] (Professor 5).

Eu sempre tive muita dificuldade com tecnologia, a ponto de muitas vezes pedir ajuda para as pessoas [...]. Durante essa pandemia eu tive que me reinventar sabendo dessa dificuldade que eu tenho, eu tive que pesquisar, estudar, porque acredito que com a curiosidade a gente consegue buscar, a gente consegue aprender e o professor está ali para buscar [...] (Professor 6).

Eu avalio como básico, então eu trabalho com aquilo que é necessário, é óbvio que nós já temos uma dificuldade para conseguir de fato compreender todas as tecnologias, manusear a ferramenta e tal, aquilo que é básico nós temos 
trabalhado procuramos melhorar utilizando uma ou outra ferramenta que nós conhecemos em cursos, compartilhando experiências, mas eu ainda acredito que eu tenho dificuldades sim, apesar da pouca idade porque a gente pensa quanto mais novo mais englobado nas ferramentas tecnológicas, mas eu acredito que eu ainda tenho muito que aprender e que tenho bastante dificuldade (Professor 10).

Então, eu nunca fui muito adepto as tecnologias, nunca tive muita facilidade, mas assim sempre o básico das tecnologias a gente sempre procurou dar conta [...] (Professor 11).

As respostas deixam evidente a dificuldade dos professores relacionada a utilização das tecnologias digitais, apresentado nas falas como um conhecimento básico. Podemos perceber que uma habilidade exigida e de importância significativa no período de aulas remotas passou a se fazer presente de forma repentina, exigindo que os professores se adaptassem ao novo método de ensino.

Com a mudança repentina do ensino presencial para o remoto, os professores passaram a enfrentar um grande desafio relacionado a utilização de tecnologias digitais, visando o melhor desempenho dos estudantes, não havendo preparação, planejamento e formação docente para o uso de ferramentas digitais (Ferreira \& Barbosa, 2020).

O processo de ensino-aprendizagem é complexo, cada aluno possui ritmos de processos de aprendizagem diferentes, sendo evidenciado essas dificuldades no ensino remoto. "Os processos de ensinar e aprender não são tão simples de serem resolvidos apenas por recursos tecnológicos. Lidar com seres humanos é complexo, os ritmos, os tempos e os processos de aprendizagem são diferentes" (Honorato \& Marcelino, 2020, p. 213).

Pudemos perceber que o ERE surgiu a partir da necessidade de se dar continuidade às aulas. Ocorreu de maneira repentina, devido a sua necessidade de implantação; e houve algumas formações continuadas a respeito da implantação desse novo modelo de ensino, mas que não conseguiram suprir as dificuldades enfrentadas pelos professores em relação a utilização das tecnologias digitais, pois se fez necessário a adaptação a esse meio tecnológico em um curto espaço de tempo.

O próximo eixo elencado foi: dificuldades encontradas com processo ensino aprendizagem. Originou-se a partir da indagação realizada que questionou os sujeitos sobre quais foram as maiores dificuldades encontradas no processo ensino aprendizagem para lecionar a Educação Física neste modelo (ERE).

As respostas dos sujeitos evidenciaram duas das maiores dificuldades encontrada no processo de ensino aprendizagem: não conseguir alcançar todos os estudantes durante as aulas remotas e a realização das práticas corporais. A primeira dificuldade apontada foi observada nos textos abaixo:

Acho que a maior dificuldade é conseguir atingir todos os alunos, então principalmente no início, agora esse ano que eu acredito que tá um pouco melhor, mas quando começou o ensino remoto a gente não conseguia atingir todos os alunos [...] (Professor 2).

Eu acho que a maior dificuldade mesmo, para mim é o central, o principal, é aluno, por que você conseguir alcançar esses alunos e alcançar de uma forma com educação com qualidade foi muito difícil com esse sistema remoto, por vários aspectos, então para mim a maior dificuldade realmente não foi nem sobre organizar conteúdos, não foi nem sobre organizar aulas, não foi nem sobre organizar a temática e o planejamento, a maior dificuldade não foi essa, a maior dificuldade realmente é de você chegar nesse aluno (Professor 3).

Eu acredito que adequar as atividades para que os alunos pudessem fazê-las em casa e inicialmente foi chegar nesses alunos, como eu disse a gente dependia dos pais, depende até hoje [...] (Professor 8).

Podemos perceber por meio das falas dos professores entrevistados que há uma grande preocupação relacionada a não conseguir alcançar os estudantes em sua totalidade durante o ensino remoto. Corroborando com a fala dos professores entrevistados, (Godoi, et al., 2021) destacaram em seus estudos que um dos grandes desafios relacionados ao ERE está na dificuldade de acesso às tecnologias digitais e acesso à internet por parte dos estudantes, o que faz com que não haja eficiência em atingir a todos, evidenciando ainda mais a desigualdade. Algo muito preocupante, pois muitos estudantes não estão conseguindo acompanhar as aulas. 
Outro fator que pode estar relacionado as possíveis dificuldades de acompanhamento das aulas remotas seria o apoio familiar, acompanhamento e auxílio nas atividades. Segundo Saraiva-Junges \& Wagner (2016, p. 83),

[...] o envolvimento dos progenitores tem efeitos positivos na vida acadêmica dos filhos, pois através do auxílio e interação na realização das tarefas de casa, encorajamento verbal e reforço de comportamentos desejados, monitoramento das atividades diárias e participação em reuniões, discussões e atividades escolares, os pais contribuem para o melhor aproveitamento e sucesso acadêmico das crianças e jovens.

É interessante pontuar que a citação de Saraiva-Junges \& Wagner (2016) refere-se a um período anterior ao período de aulas remotas, porém já se via a necessidade da participação da família na vida escolar do aluno. Com o início das aulas remotas, onde os estudantes perderam a presença física e direta do professor, a família se faz ainda mais necessária para a vida escolar dos estudantes, tendo como papel apoiar, auxiliar e incentivar a aprendizagem. "Importantes para o desenvolvimento do processo ensino-aprendizagem. Entende-se que a escola não existe sem professores, sem alunos, sem corpo pedagógico administrativo e sem a família" (Honorato \& Marcelino, 2020, p. 211).

A outra dificuldade relacionada ao processo de ensino aprendizagem foi a realização das práticas corporais da Educação Física, como se observa nos textos abaixo:

A principal dificuldade é conseguir alinhar aí o procedimental com conceitual no ensino remoto, a gente tá nessa característica apostilado que a gente só tem como ser o conceitual e quem tá online também não aparecem, muitos não aparecem, então fica só no conceitual a parte da educação física [...] (Professor 5).

A minha maior dificuldade é pensar nas práticas, essa questão de adaptar, no sentido de pensar no que o aluno tem em casa e o aluno ele não tem as vezes nem uma bola em casa, muitas vezes eu pensei: ah vou precisar de uma bola para determinada atividade, para trabalhar arremesso, para trabalhar lançamento de bola, fiz oficinas de bola de meia, bola de papel, mas a gente sabe que esses materiais alternativos nem sempre eles suprem a necessidade (Professor 6).

[...] Essa é uma das maiores angustias eu percebo dos professores de educação física, porque a gente perdeu o elo prático, então todas as atividades que a gente pensa ela acaba ficando muitas vezes no cunho teórico, eu acho assim que toda aquela questão de fazer o trabalho, com a interação com o estudante, com a socialização ali, isso acabou se perdendo e a gente trabalha muito agora no campo teórico, a gente ficou preso nesse campo teórico, algumas atividades você consegue desenvolver através de vídeos, porém a interação acabou se perdendo, então isso foi um limitante muito grande na questão do encaminhamento das aulas de educação física. (Professor 11).

Percebe-se através das falas dos professores entrevistados que a Educação Física perdeu uma das suas principais características enquanto componente curricular, relacionar as dimensões conceituais com as procedimentais. Isso fez com que a Educação Física se tornasse um componente apenas conceitual e as dificuldades enfrentadas nas aulas de Educação Física passaram a ser outras.

As aulas passaram a acontecer apenas de maneira teórica, levantando preocupações, gerando um misto de emoções, pois não há mais contato físico, o que acontecia com a realização das práticas corporais e interações proporcionadas pelos jogos, esportes, dança, ginástica e lutas nas aulas de educação física (Godoi, et al., 2020).

A mudança do ensino presencial para o ensino remoto gerou preocupações em como o componente aconteceria de maneira remota, pois não haveria mais o contato físico, a realização das práticas corporais em grupos e as aulas aconteceriam das residências dos estudantes. Assim, a Educação Física passou a perder um pouco da sua identidade, algo sempre elencado em documentos educacionais.

O componente curricular Educação Física sempre apresentou grande enfoque em atividades práticas, com possibilidades de experimentação e vivências culturais, proporcionando saberes e experiências, assim como é apresentado na BNCC:

É fundamental frisar que a Educação Física oferece uma série de possibilidades para enriquecer a experiência das crianças, jovens e adultos na Educação Básica, permitindo o acesso a um vasto universo cultural. Esse universo compreende saberes corporais, experiências estéticas, emotivas, lúdicas e agonistas, que se inscrevem, mas não se 
restringem, à racionalidade típica dos saberes científicos que, comumente, orienta as práticas pedagógicas na escola. (Brasil, 2017, p. 213).

As aulas de Educação Física passaram a enfrentar dificuldades diferentes, dessa vez relacionadas as práticas corporais, principalmente voltadas aos conhecimentos procedimentais, pois com o início das aulas remotas se perdeu a característica procedimental, não havendo possibilidade de realização das práticas corporais coletivas devido a pandemia de Covid- 19.

[...] No contexto da pandemia, evidencia-se a dificuldade estrutural em se produzir ações pedagógicas voltadas aos conhecimentos procedimentais, tendo em vista a necessidade do isolamento social e incapacidade de fomentar práticas corporais coletivas e/ou em espaços públicos com a presença de muitas pessoas. (Skowronski, 2021, p. 05).

O próximo eixo elencado foi denominado de estratégias adotadas no ERE e surgiu a partir da indagação realizada aos sujeitos de quais foram as estratégias utilizadas para lecionar as unidades temáticas da Educação Física no ERE.

Neste eixo obtivemos respostas distintas, por se tratar de professores de municípios diferentes e por cada escola possuir autonomia para adotar as suas estratégias, o que se estende a todos os componentes curriculares, inclusive a Educação Física.

[...] Nós estamos assim priorizando mais a abordagem conceitual e atitudinal dos conteúdos, a parte procedimental está ficando, então assim nós estamos atendendo todas as demandas, as habilidades que são postas [...] (Professor 1).

Olha a estratégia que eu utilizo, algumas das temáticas, das unidades temáticas realmente a gente trabalha apenas na dimensão conceitual, isso realmente não tem como e algumas temáticas, um exemplo que eu posso citar é os jogos por exemplo, a temática de jogos eu consigo fazer algumas estratégias para eles poderem vivenciar entre os entes familiares [...] (Professor 3).

As minhas aulas são conceituais, só trabalho com a teoria, a prática eu tentei trabalhar ano passado, nesse ano eu desisti, então durante as aulas quando eu posso eu até peço para eles levantarem, fazerem alguma coisa, mas no contexto geral são teóricas [...] (Professor 7).

Com a fala dos professores entrevistados, percebemos que as aulas são voltadas apenas para o cunho teórico, algo já relatado como dificuldade no eixo anterior. Devido ao momento que ainda vivenciamos de aulas de forma remota, a Educação Física ganhou um grande destaque no que diz respeito a teoria, algo que não era visto com grande destaque nas aulas presenciais. Pode- se notar que desde o início do ensino remoto os professores precisaram se reinventar para dar continuidade as aulas, o que não foi diferente com a Educação Física, as estratégias adotadas são as que mais se encaixam dentro do ambiente escolar vivenciado pelos professores.

Outra estratégia relatada foi a utilização do WhatsApp ${ }^{\circledR}$ como ferramenta utilizada para as aulas remotas.

Então, na minha escola em reunião com todos os professores a gestão decidiu utilizar o WhatsApp ${ }^{\circledR}$, acredito que grande parte das escolas está usando esse aplicativo também porque é o aplicativo do momento, ele é o mais utilizado, mais acessível, as vezes o aluno adquiri um plano de internet e o pacote de WhatsApp ${ }^{\circledR a ́}$ vem de forma gratuita mesmo se o aluno não tem internet as vezes ele consegue utilizar [...] (Professor 6).

Mesmo não sendo uma plataforma oficial de estudos, o WhatsApp® contribui muito devido a sua facilidade de acesso e o consumo baixo de internet, o que facilita o contato da escola com os estudantes e familiares. Em diálogo, autores indicam que

Vale observar que o WhatsApp® é um aplicativo de mensagens de smartphone e não um Ambiente Virtual de Aprendizagem nos moldes da Educação à Distância. Porém as escolas têm utilizado esta ferramenta por ser de mais fácil acesso para os pais e alunos da escola pública do que tablets e computadores. (Godoi, et al., 2021, p.10) 
Durante a realização desse estudo percebemos de forma clara que as estratégias foram adotadas de acordo com a realidade escolar, com o intuito de alcançar os estudantes em sua totalidade. Ao encontro disso, tivemos um relato de estratégia utilizada através da produção e entrega de materiais apostilados aos estudantes.

[...] Nós temos poucos estudantes que tem acesso à internet e nós trabalhamos bastante com material impresso, onde os estudantes retiram na escola, a gente faz entrega para grande parte deles e aí essa tá sendo uma das estratégias adotadas pela unidade escolar, não somente pela minha área [...] (Professor 11).

A implementação do ensino remoto trouxe mudanças significativas nas organizações escolares e nas estratégias utilizadas nas aulas dos professores de Educação Física. Ao se pensar nas estratégias possíveis para as aulas de Educação Física, se faz necessário compreender o público escolar.

Nosso próximo questionamento envolveu quais seriam as possíveis contribuições que a experiência em lecionar no modelo ERE poderiam ser levadas ao ensino presencial, quando este retornar. O eixo temático que se originou foi contribuições do ensino remoto para o ensino presencial.

Eu creio que sim, porque quando você tá no presencial, até então a gente conhecia as crianças na escola, só ali naquele ambiente e eu acho que por mais que você está distante, você acaba entrando dentro da casa da criança, então você acaba conhecendo o ambiente onde que ele vive, com quem que ele se relaciona. Então assim eu acho que isso muito pode contribuir para que a gente possa atender de maneira melhor a criança (Professor 4).

Eu tenho pensado muito nisso, eu acho que com certeza a gente vai ter por exemplo a possibilidade mais intensa, tanto do aluno o uso intenso do próprio WhatsApp ${ }^{\circledR}$ e a gente transformar isso. A minha escola, por exemplo não tinha grupos de alunos pelo WhatsApp ${ }^{\circledR}$, então eu acho que isso se tornou uma forma de comunicação muito rápida e permite nesses grupos você mandar atividades, mandar questões que podem ser complementadas para o aluno (Professor 9).

Olha eu acredito que sim, eu acho que o próprio sair mesmo do conforto, de nos obrigar a conhecer um pouco mais a tecnologia, essas ferramentas tecnológicas, utilizar mais ferramentas isso também contribui para dinamizar a aula, por quê tem estudantes que gostam [...] (Professor 10).

A gente quase não tinha comunicação com esses pais, até tinha, mas era muito em reunião de pais e nem sempre aparecia a maioria de pais e mães, então esse contato maior com a família, que a gente conseguiu entrar dentro da casa de cada um, assim como eles também estão mais presentes na vida da gente diariamente (Professor 8).

É notório que a pandemia proporcionou inúmeras mudanças, tanto em relação ao convívio social, como a forma em que as aulas passaram a ser conduzidas através do ensino remoto. A partir das falas dos professores entrevistados percebemos que são várias as contribuições adquiridas com o ensino remoto, principalmente relacionado a proximidade com a família dos estudantes, algo que acontecia somente em reunião de pais ou entrega de notas.

A proximidade com a família é algo muito importante no processo de ensino e aprendizagem, pois o auxílio familiar pode favorecer o desempenho escolar, tendo em vista que a criança permanece na escola em um curto período, enquanto o convívio familiar é muito maior (Souza, 2009).

Outra contribuição identificada está relacionada a utilização de tecnologias digitais. O início do ensino remoto fez com que a utilização de tecnologias nas aulas avançasse de maneira significativa em pouco tempo, devido à necessidade em que os estudantes continuassem as aulas de casa.

Antes da implantação do ERE, a utilização de tecnologias de informação e comunicação (TICs) era inserida de forma gradativa nas aulas, assim como os conhecimentos acerca dessas tecnologias também eram adquiridas aos poucos pelos professores. Algo que mudou de maneira significativa após o início do ERE. Mesmo que o ERE tenha acontecido de maneira repentina, este proporcionou a utilização das TICs de maneira mais efetiva nas aulas.

Os professores estavam acostumados com as aulas presenciais e de forma rápida foi preciso mudar a forma como as aulas aconteciam devido à necessidade da implantação do ERE. Nesse cenário, passou a se fazer necessário a utilização de TICs, 
substituindo a sala de aula pelo ambiente domiciliar. As aulas que aconteciam sempre no mesmo espaço, passaram a acontecer por gravações de vídeos, videoconferências e/ou podcasts, buscando sempre contribuir com a aprendizagem dos estudantes (Ferreira a, et al., 2020).

\section{Considerações Finais}

A pandemia da Covid-19 modificou de maneira brusca a nossa forma de viver e isso não foi diferente com a educação. Em um curto período as aulas se modificaram, fazendo com que estudantes, família, professores e a escola se adaptassem ao novo método de ensino. Evidenciando as dificuldades relacionadas a esse novo método, relacionado ao acesso as tecnologias por parte de professores e estudantes.

A implementação do ERE surgiu a partir da necessidade de dar continuidade ao ano letivo, se iniciando de maneira emergencial e sem planejamento, exigindo dos professores conhecimentos tecnológicos que antes não eram utilizados com frequência no ensino presencial. Além disso, estudantes que não possuem acesso as tecnologias e a internet não conseguiram acompanhar as aulas de maneira eficiente. No âmbito da Educação Física, as dificuldades se tornaram ainda mais evidentes, pois as aulas passaram a acontecer com mais frequência de maneira conceitual e buscando sempre a utilização de outros meios e estratégias para que o maior número de estudantes pudesse ser alcançado.

Ao analisarmos a percepção dos professores sobre os desafios enfrentados no ensino da Educação Física durante o período de aulas remotas, identificamos que o nosso objetivo de pesquisa foi respondido, pois os professores percebem que muitos foram os desafios enfrentados, tanto relacionados a utilização de tecnologias e o não acesso a todos, como dificuldades relacionadas as incertezas que surgiam com essa nova modalidade de ensino. Tais desafios proporcionaram buscas de estratégias que pudessem contribuir com o processo de ensino e aprendizagem dos estudantes durante o ERE. Ademais, foi possível identificar que além dos desafios também surgiram contribuições para a formação profissional dos professores, que veem possíveis mudanças em suas práticas pedagógicas com o retorno do ensino presencial.

Assim, vê-se que o ERE trouxe consigo dificuldades, estas relacionadas a utilização das TICs, adaptações no ambiente domiciliar para que as aulas pudessem acontecer, assim como a busca constante por metodologias que contribuíssem com o processo de ensino e aprendizagem. Apesar das dificuldades enfrentadas, o ERE contribui muito para a formação profissional dos professores, a busca por metodologias visando o alcance de forma significativa dos estudantes, percebendo que a sua realidade e dificuldade foi algo muito significativo para o retorno do ensino presencial.

Ainda, percebemos que o ensino remoto contribuiu para a proximidade dos professores com os familiares dos estudantes, pois o momento pandêmico exigiu que a escola e os pais trabalhassem juntos para que os estudantes conseguissem acompanhar as aulas de maneira remota. Os professores passaram a se fazer presente dentro do ambiente familiar, assim como os familiares puderam conhecer um pouco mais sobre os professores de seus filhos. O elo família e escola se fizeram extremamente necessários para a continuidade da aprendizagem dos estudantes. Dessa forma, devido à grande proximidade da família com o ambiente familiar, algo necessário para o processo de ensino e aprendizagem dos estudantes, ficou evidente que é preciso que a escola e a família caminhem juntas, visando contribuir com a aprendizagem dos estudantes. Essa relação precisa permanecer quando houver o retorno das aulas presenciais.

Ao realizarmos essa pesquisa compreendemos que muito tem se discutido sobre essa modalidade de ensino, mas é algo necessário, pois houve uma grande modificação no sistema de ensino e aconteceu de forma repentina. Assim, pesquisas como essa são relevantes e essenciais, sobretudo ouvindo relatos dos próprios atores que vivenciaram e vivenciam em suas rotinas de trabalho as mudanças, os desafios e as contribuições do atual cenário educacional. 


\section{Referências}

Betti, M., \& Zuliani, L. R. (2002). Educação física escolar: uma proposta de diretrizes pedagógicas. Conexões, 19(1), 73-81. https://doi.org/10.20396/conex.v19i1.8660781

Brasil. (2017). Base Nacional Comum $\quad$ Curricular $\quad$ (BNCC). http://basenacionalcomum.mec.gov.br/images/BNCC_EI_EF_110518_versaofinal_site.pdf

Brasil. (2020). Ministério da Educação. Gabinete do Ministro. Portaria no 343, de 17 de março de 2020. Dispõe sobre a substituição das aulas presenciais por aulas em meios digitais enquanto durar a situação de pandemia do Novo Coronavírus - Covid-19. Diário Oficial da União, Brasília, DF, ed. 53, 18 mar., seção 01, p. 39. https://www.in.gov.br/en/web/dou/-/portaria-n-343-de-17-de-marco-de-2020-248564376

Castaman, A. S. \& Rodrigues, R. A. (2020). Educação a Distância na crise COVID - 19: um relato de experiência. Research, Society and Development, 9(6), e180963699. https://doi.org/10.33448/rsd-v9i6.3699.

Ferreira, L. H. \& Barbosa, A. (2020). Lições de quarentena: limites e possibilidades da atuação docente em época de isolamento social. Praxis Educativa, 15, 1-25. https://doi.org/10.5212/praxeduc.v.15.15483.076

Ferreira, V. M. S., Oliveira, T. R. H. \& Silva, M. I. F. D. (2020). Desafios em tempos de pandemia: o ensino remoto emergencial da Educação Física no Ensino Fundamental. In: Anais do Congresso Internacional de Educação e Tecnologias, Encontro de Pesquisadores em Educação a Distância, CIET: EnPED, São Carlos, ago. https://cietenped.ufscar.br/submissao/index.php/2020/article/view/1272

Garcia, M. F., Rabelo, D. F., Silva, D. da \& Amaral, S. F. do. (2012). Novas Competências Docentes Frente Às Tecnologias Digitais Interativas. Teoria e Prática Da Educação, 14(1), 79-87. https://doi.org/10.0000/rtpe.v14i1.16108

Gil, A. C. (2008). Métodos e técnicas de pesquisa social. Editora Atlas S. A. https://ayanrafael.files.wordpress.com/2011/08/gil-a-c-mc3a9todos-e-tc3a9cnicasde-pesquisa-social.pdf

Godoi, M., Kawashima, L. B. \& Gomes, L. D. A. (2020). "Temos que nos reinventar": os professores e o ensino da educação física durante a pandemia de COVID-19. Dialogia, 36, 86-101. https://doi.org/10.5585/dialogia.n36.18659

Godoi, M., Kawashima, L. B., Gomes, L. de A. \& Caneva, C. (2021). As Práticas Do Ensino Remoto Emergencial De Educação Física Em Escolas Públicas Durante a Pandemia De Covid-19: Reinvenção E Desigualdade. Revista Prática Docente, 6(1), e012. https://doi.org/10.23926/rpd.2021.v6.n1.e012.id995

Hodges, C., Trust, T., Moore, S. \& Bond, A. (2020). Diferenças entre o aprendizado online e o ensino remoto de emergência. Revista Da Escola, Professor, Educação e Tecnologia, 2, 1-12. http://escribo.com/revista/index.php/escola/article/view/17

Honorato, H. G. \& Marcelino, A. C. K. B. (2020). A arte de ensinar e a pandemia covid-19: a visão dos professores. REDE - Revista Diálogos em Educação, 1(1), 208-220, jan./jun. https://forms.gle/Jx1kgHqgT4nbxSRf6

Minayo, M. C. De S. (Org), Deslandes, Suely. Ferreira.; Gomes, Romeu. (2007). Pesquisa social: teoria, método e criatividade. Petrópolis, Rio de Janeiro: Editora Vozes, 30. Ed.

Moreira, J. A. \& Schlemmer, E. (2020). Por um novo conceito e paradigma de educação digital onlife. Revista UFG, 20, 1-35. https://doi.org/10.5216/revufg.v20.63438

Prodanov, C. C. \& Freitas, E. C. (2013). Metodologia do trabalho científico: métodos e técnicas da pesquisa e do trabalho acadêmico. Novo Hamburgo, Rio Grande do Sul: Universidade Feevale. https://aedmoodle.ufpa.br/pluginfile.php/291348/mod_resource/content/3/2.1-E-book-Metodologia-do-TrabalhoCientifico-2.pdf

Rinaldi, R. P. (2009). Desenvolvimento profissional de formadores em exercício: contribuições de um programa online. Tese (Doutorado em Educação), Programa de Pós-Graduação em Educação, Universidade Federal de São Carlos, São Carlos/SP. https://repositorio.ufscar.br/handle/ufscar/2225

Rodrigues, A. (2020). Ensino remoto na Educação Superior: desafios e conquistas em tempos de pandemia. Horizontes, jun. https://horizontes.sbc.org.br/index.php/2020/06/ensino-remoto-na-educacao-superior/

Rufino, L. G. B., Benites, L. C. \& Souza Neto, S. de. (2017). Os desafios para o desenvolvimento do trabalho docente na perspectiva de professores de Educação Física. Corpoconsciência, 21(3), 55-65.

Saraiva-Junges, L. A. \& Wagner, A. (2016). Os estudos sobre a Relação Família-Escola no Brasil: uma revisão sistemática. Educação, Porto Alegre, 39, S114S124, dez. https://doi.org/10.15448/1981-2582.2016.s.21333

Skowronski, M. (2021). Práticas corporais para além das quadras: educação física escolar ao alcance de todos no ensino remoto. In: Anais do $10^{\circ}$ Simpósio Internacional de Educação e Comunicação, 1-15. https://eventos.set.edu.br/simeduc/article/view/14873/6401

Souza, M. E. P. (2009). Família/Escola: a importância dessa relação no desenvolvimento escolar. Programa de Desenvolvimento Educacional, Secretaria de Estado da Educação do Paraná, Santo Antônio da Platina. http://www.diaadiaeducacao.pr.gov.br/portals/pde/arquivos/1764-8.pdf 